\title{
A High-throughput Strategy for Glycine Oxidase Biosensor Development Reveals Glycine Release from Cultured Cells
}

\author{
Siba Moussa ${ }^{\mathrm{a}}$, Elena Rosini ${ }^{\mathrm{b}}$, Daryan Chitsaz ${ }^{\mathrm{c}}$, Loredano Pollegioni ${ }^{\mathrm{b}}$, Timothy E. Kennedy ${ }^{\mathrm{c}}$, \\ Janine Mauzeroll ${ }^{\mathrm{a}}$
}

\footnotetext{
aDepartment of Chemistry, McGill University, 801 Sherbrooke Street West, H3A 0B8, Montreal, Quebec, Canada H3A 0B8

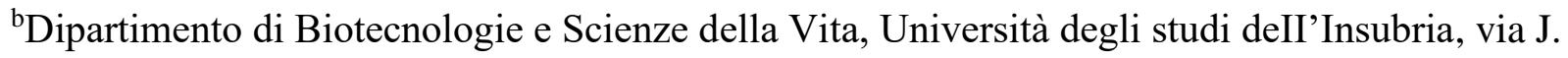
H. Dunant 3, 21100 Varese, ltaly

${ }^{c}$ McGill Program in Neuroengineering, Department of Neurology and Neurosurgery, Montreal Neurological Institute, McGill University, H3A 2B4, Montreal, QC, Canada
} 
Table of Contents

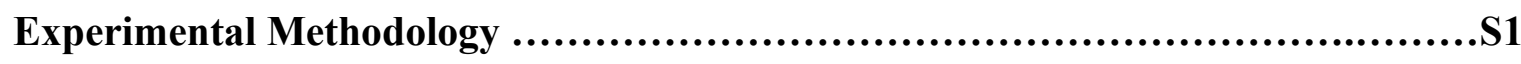

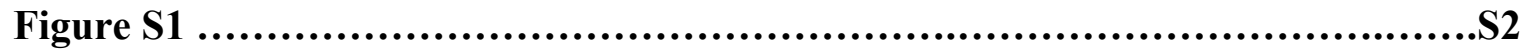

Figure $\mathbf{S 2}$.............................................................................

Table $\mathbf{S 1}$....................................................................S4

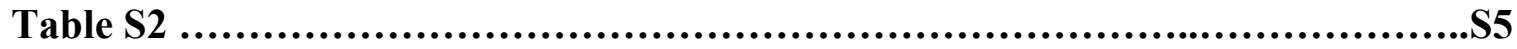

Figure $\mathbf{S 3}$.......................................................................S6

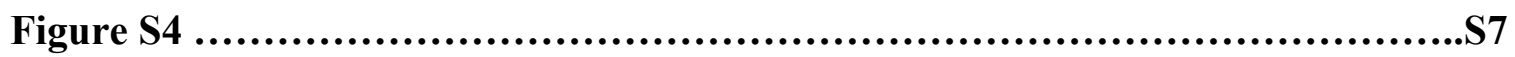

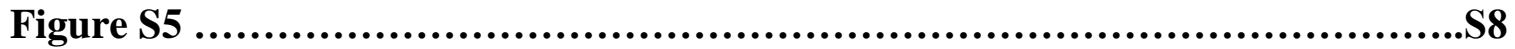

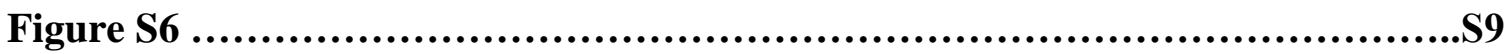

Figure $\mathbf{S 7}$....................................................................S10 


\section{Experimental Methodology}

DNA Sequencing of clones. DNA corresponding to clones of interest was isolated using gel extraction and PCR cleanup (Macherey Nagel). Briefly, 10-50 $\mu \mathrm{L}$ of crude extracts were inoculated in $3 \mathrm{~mL} \mathrm{LB}$ with Amp and Cam. DNA from $1.5 \mathrm{~mL}$ of the cultures was isolated and agarose gel electrophoresis was used to extract the band corresponding to the pT7-GO DNA. The DNA was excised and eluted with $50 \mathrm{~mL}$ AE buffer (10 mM Tris-Cl, $0.5 \mathrm{mM}$ EDTA, pH 9.0.). Ultracompetent JM109 E.coli cells were transformed using 5-10 $\mu \mathrm{L}$ of the DNA and the pT7 expressing cells were plated on $100 \mu \mathrm{g} / \mathrm{mL}$ Amp and $100 \mu \mathrm{g} / \mathrm{mL}$ Cam containing LB agar plates. A single colony from each plate was picked for inoculation in $10 \mathrm{~mL} \mathrm{LB}$ (with antibiotics). The pT7 plasmid DNA was extracted from the ultracompetent cells, eluted with $50 \mu \mathrm{L}$ milliQ water and used for sequencing (Milan, Italy).

Well Plate Preparation for Electrochemical Measurements. Well plates were prepared by cleaning a microscope glass slide. The glass slide was modified with adhesive tape which had $4 \times 5$ rectangular grids printed on the surface. The modified glass slide was coated in polydimethylsiloxane (PDMS) and stored in an oven overnight at $120^{\circ} \mathrm{C}$. After 24 hours, a surgical knife was used to remove the PDMS from the regions within the rectangular boxes, creating evenly spaced wells with hydrophobic walls to contain liquid within.

Null Experiments with PPD-ME and GO. PPD-MEs were immersed in a solution of PBS buffer. A constant potential of $0.5 \mathrm{~V}$ was applied at the tip of the PPD-MEs and the current was monitored. After a period of 5 minutes, a cell suspension of HEK 293 cells (100 $\mu \mathrm{L})$ was transferred to the well plate and the current at $0.5 \mathrm{~V}$ was measured. After a period of 10 mins, 2

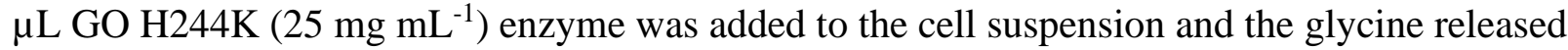
from HEK 293 cells was monitored indirectly through hydrogen peroxide production.

Interference effect of Triton X-100 and Tween-20. GO H244K biosensors were immersed in $200 \mu \mathrm{L}$ PSB buffer. A constant potential of $0.5 \mathrm{~V}$ was applied at the tip of the biosensors and following recording baseline currents in PBS, $2 \mu \mathrm{LTriton} X-100$ was added to the buffer solution to form a $1 \%$ Triton X-100 solution. The same experimental protocol was repeated with Tween20 .

LC-MS Experiments. A previously published protocol was used to prepare the LC-MS samples. ${ }^{1}$ Briefly $50 \mu \mathrm{L}$ of each sample was derivatized with $25 \mu \mathrm{L} 0.5 \%$ Marfey's reagent (wt/vol in acetone) and $50 \mu \mathrm{L} 0.125 \mathrm{~mol} / \mathrm{L}$ anhydrous disodiumtetraborate (in milli-Q-water) for 30 min at $40{ }^{\circ} \mathrm{C}$ under drying with a nitrogen steam. The reaction was stopped by addition of $12.5 \mu \mathrm{L} 4 \mathrm{M} \mathrm{HCl}$. The resulting solution was diluted (1:10) with eluent buffer $(250 \mathrm{mg}$ ammonium formate in $1 \mathrm{~L}$ milli-Q-water; $\mathrm{pH}$ adjusted to 4.6 with formic acid). The resulting sample was centrifuged (BioRad, $4000 \mathrm{rpm}, 10 \mathrm{mins}$ ) and $10 \mu \mathrm{L}$ of the supernatant were subjected to LC-MS using electrospray ionization (ESI) in negative ion mode. MassLynx software, which included QuanLynx (Waters), was used for instrument control, data acquisition, and data processing to obtain the area under the curve of the peaks and their retention times. 


\section{Supporting Figures}

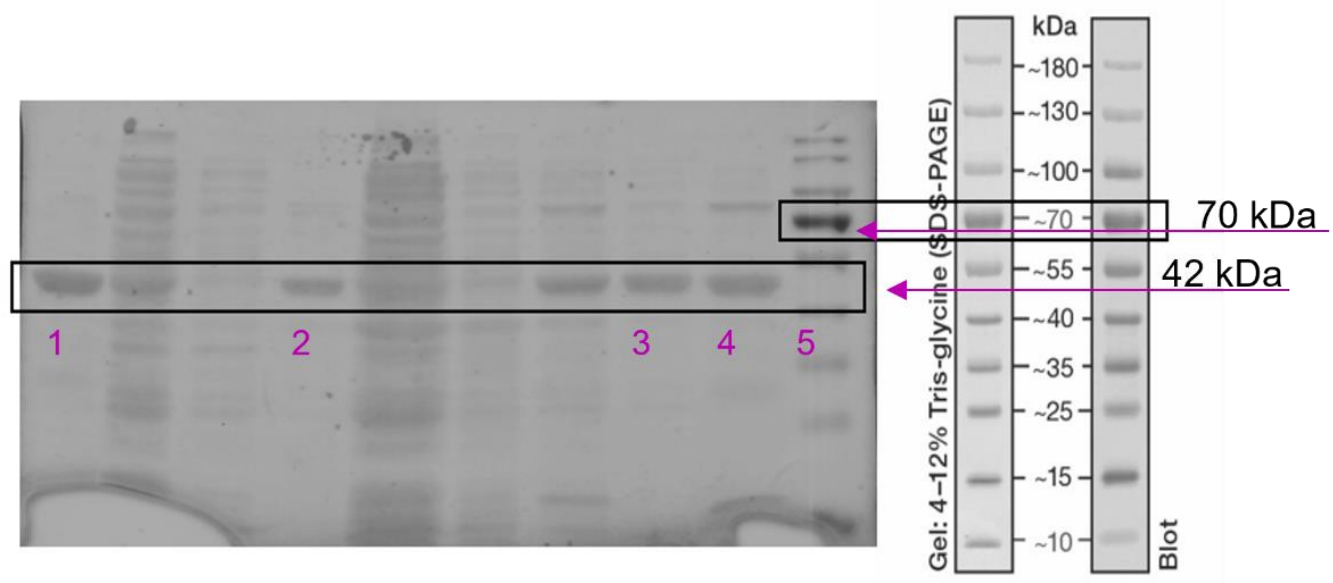

Figure S1: SDS-PAGE analysis of purity of GO preparations. Numbers correspond to: 1. GO WT, 2. H244K, 3. H244Q, 4. H244F, 5. Molecular weight marker proteins 
Table S1. Specific activity (U.mg-1) of GO wild-type and GO variants at $\mathrm{pH} 8.5$ and $25^{\circ} \mathrm{C}$ determined by o-DNS assay

\begin{tabular}{ccc}
\hline GO Mutant & Substrate & Specific Activity $\left(\mathrm{U}^{-1} \mathrm{mg}^{-1}\right)$ \\
\hline WT & $10 \mathrm{mM}$ Gly & $0.8 \pm 0.65$ \\
H244F & $100 \mathrm{mM}$ Gly & $0.523 \pm 0.10$ \\
H244K & $100 \mathrm{mM} \mathrm{Gly}$ & $1.038 \pm 0.13$ \\
H244Q & $100 \mathrm{mM} \mathrm{Gly}$ & $0.177 \pm 0.03$ \\
\hline
\end{tabular}


Table S2. Kinetic parameters for GO variants of interest at $\mathrm{pH} 8.5$ and $25{ }^{\circ} \mathrm{C}$ derived from Ref 2 .

\begin{tabular}{ccccc}
\hline & $\begin{array}{c}\mathrm{k}_{\text {cat }} \\
\left(\mathrm{s}^{-1}\right)\end{array}$ & $\begin{array}{c}\mathrm{K}_{\mathrm{M}, \mathrm{app}} \\
(\mathrm{mM})\end{array}$ & $\begin{array}{c}\mathrm{k}_{\text {cat, app }}(\mathrm{mM}) / \mathrm{K}_{\mathrm{M}, \text { app }} \\
\left(\mathrm{s}^{-1} \mathrm{mM}^{-1}\right)\end{array}$ & $\begin{array}{c}\text { Turnover Ratio } \\
(\text { variant/GO WT })\end{array}$ \\
\hline His-GO WT & $0.60 \pm 0.03$ & $0.70 \pm 0.10$ & 0.86 & 1.00 \\
His-GO H244Q & $1.21 \pm 0.06$ & $0.90 \pm 0.04$ & 1.34 & 1.55 \\
His-GO H244K & $1.35 \pm 0.05$ & $0.14 \pm 0.02$ & 9.65 & 11.22 \\
\hline
\end{tabular}



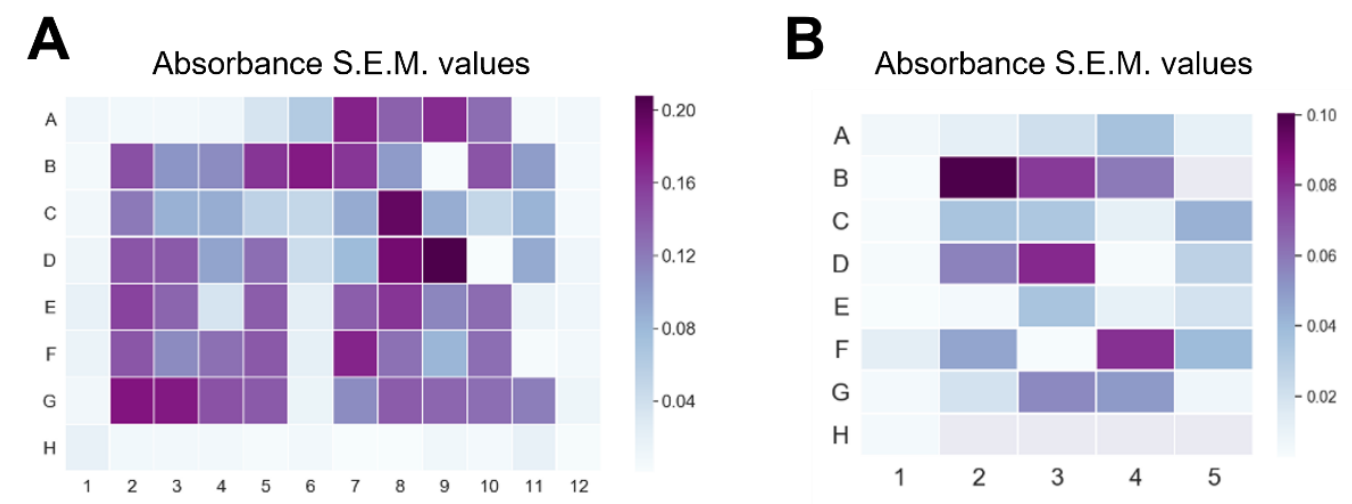

Figure S2: Corresponding S.E.M. values for the absorbance measurements as reported in the manuscript. (A) SEM values for reported absorbances in Figure 1A. Position H11 corresponds to the clone for GO WT and position H12 corresponds to the control well without cells. (B) SEM values for reported absorbances in Figure 1B. Position G5 corresponds to the clone for GO WT and position H1 corresponds to the control well without cells. Grey boxes represent empty wells. 

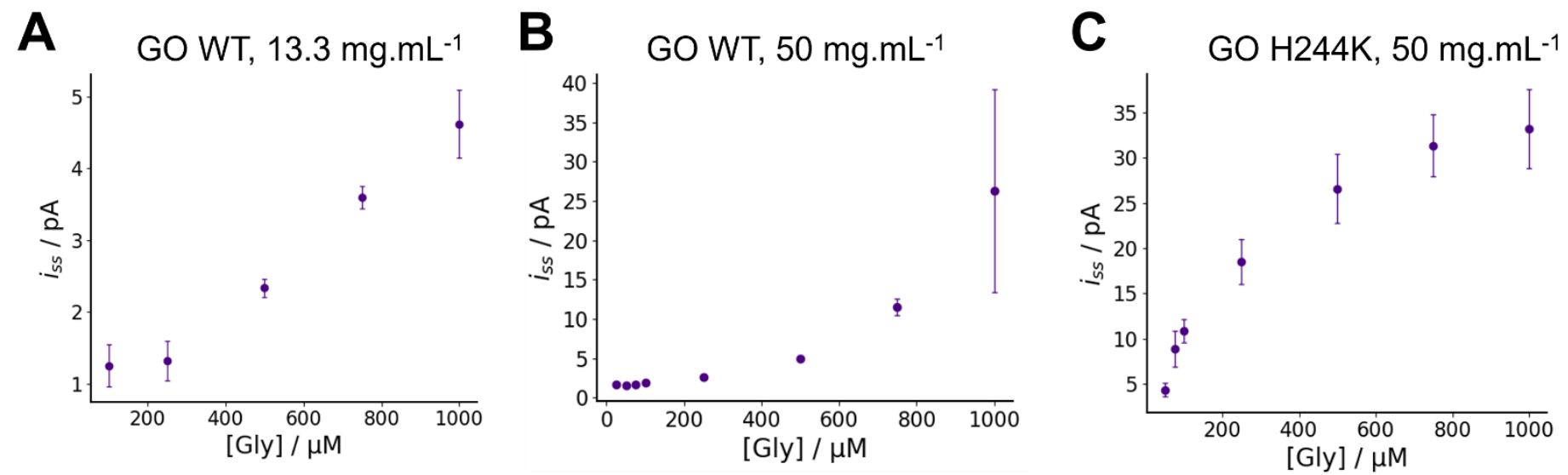

Figure S3: Calibrations of GO biosensors in standard solutions of glycine using: (A) $13.3 \mathrm{mg} \cdot \mathrm{mL}^{-1} \mathrm{GO}$ WT ; (B) 50 mg.mL ${ }^{-1} \mathrm{GO} W \mathrm{WT}$; (C) $50 \mathrm{mg} \cdot \mathrm{mL}^{-1} \mathrm{GO} \mathrm{H} 244 \mathrm{~K}$. 

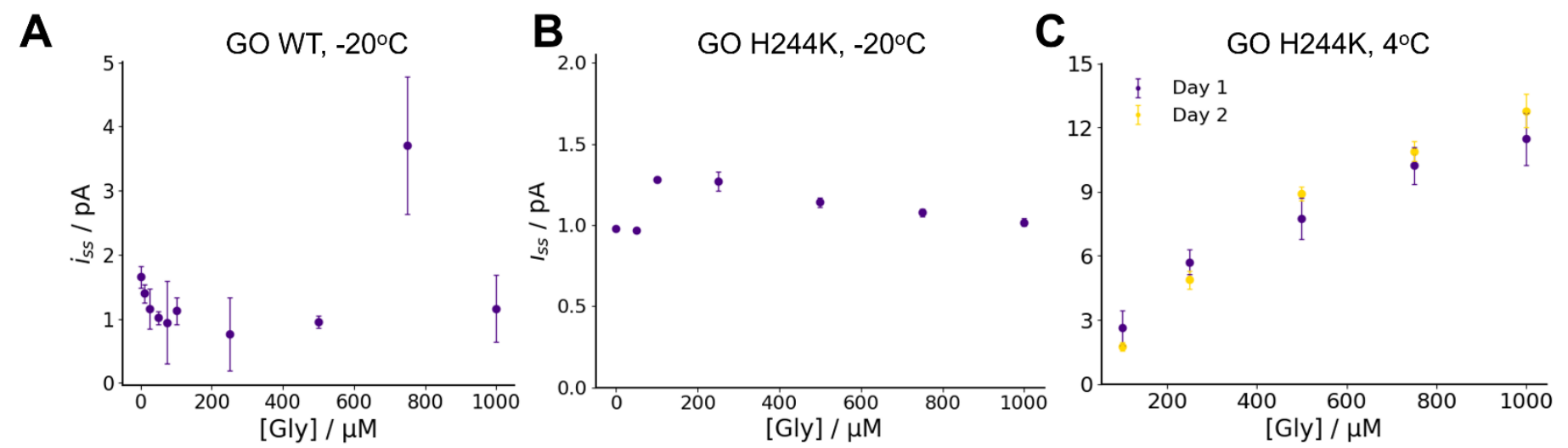

Figure S4: Calibrations of stored GO biosensors in standard solutions of glycine: (A) GO WT after 2 weeks of storage at $20{ }^{\circ} \mathrm{C}$; (B) GO H244K after 2 weeks of storage at $20{ }^{\circ} \mathrm{C}$; C) GO H244K after one day of storage at $4{ }^{\circ} \mathrm{C}$. 

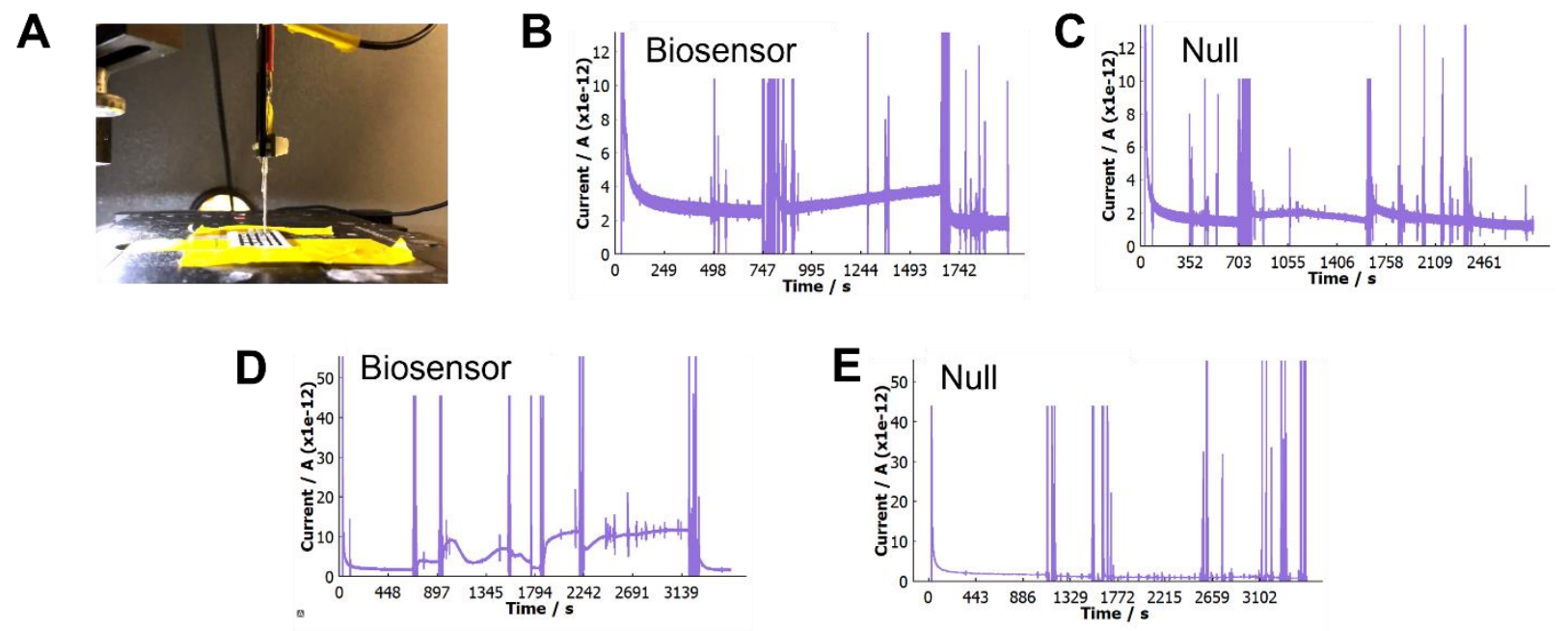

Figure S5: Application of GO H244K biosensors for real-time detection of glycine. (A) Photograph of experimental setup. (B) Representative experimental curve from the biosensor placed in PBS, followed by HEK 293 cells, followed by PBS. (C) Representative experimental curve from the null sensor placed in PBS, followed by HEK 293 cells, followed by PBS. (D) Representative experimental curve from the biosensor placed in PBS, followed by astrocytes, followed by PBS. (E) Representative experimental curve from the null sensor placed in PBS, followed by astrocytes, followed by PBS. The spikes during measurements in B-F correspond to external noise from movement in the lab space, uncompensated for with the potentiostat. The i-t traces are filtered using a Savitsky-Golay filter to remove this noise and provide more accurate readings. 
A

B
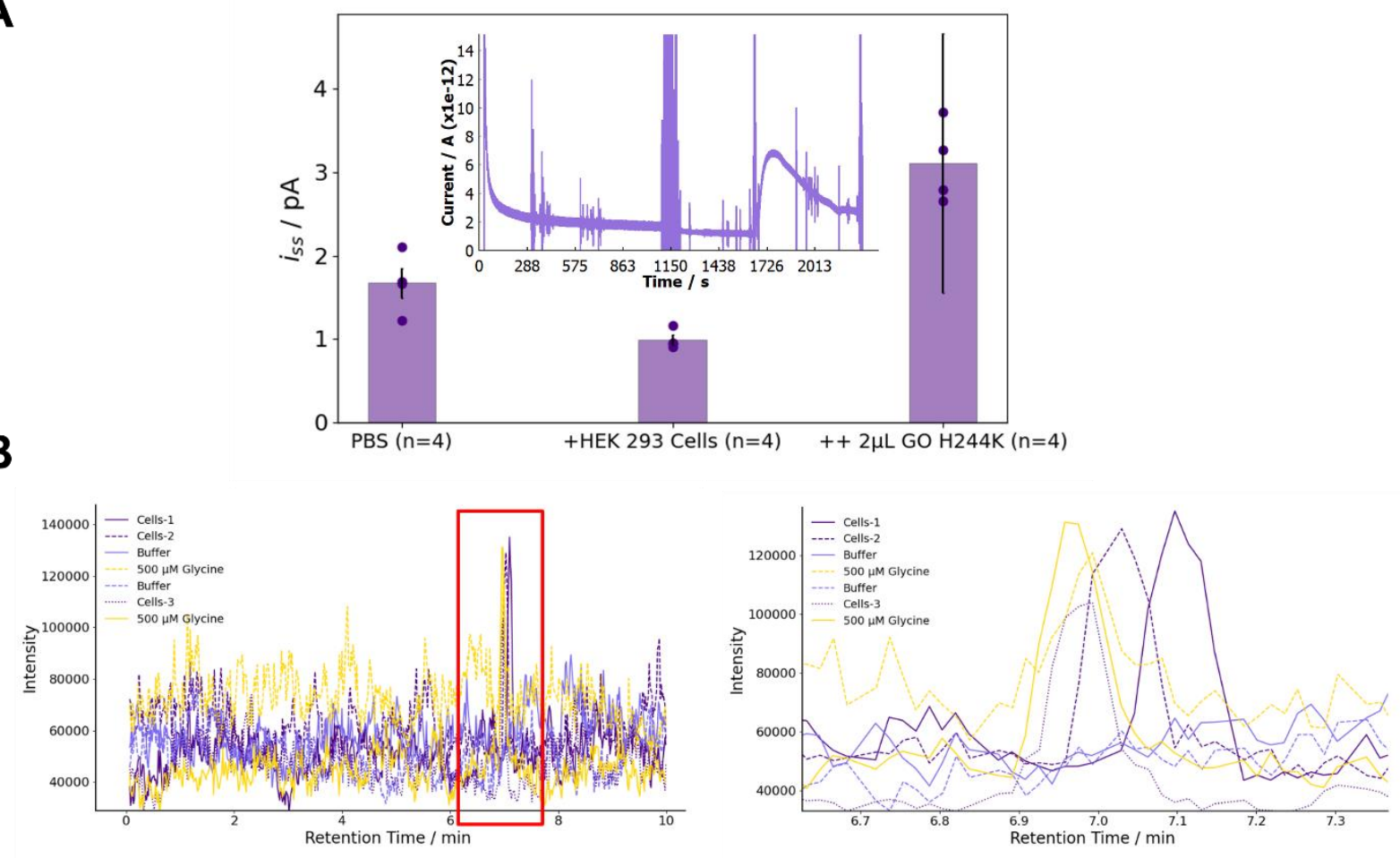

Figure S6: Validation of biosensor measurements with (A) the PPD-ME immersed in PBS, followed by cells and followed by the addition of $2 \mu \mathrm{L}$ GO H244K enzyme $(50 \mathrm{mg} / \mathrm{mL})$. The current corresponding to the application of $0.5 \mathrm{~V}$ was monitored throughout the entire length of the experiment (inset). The steady state current was extracted and demonstrates glycine turnover by the addition of GO H244K to the HEK 293 cells. (B) LC-MS experiments where the peak at 6.90-7.00 corresponds to the glycine presence. Left: Full chromatogram corresponding to all experiments. Right: Zoomed-in portion of chromatogram to show presence of glycine for cell samples (dark purple) and glycine (gold) and lack of presence of glycine in buffer (light purple). 
A

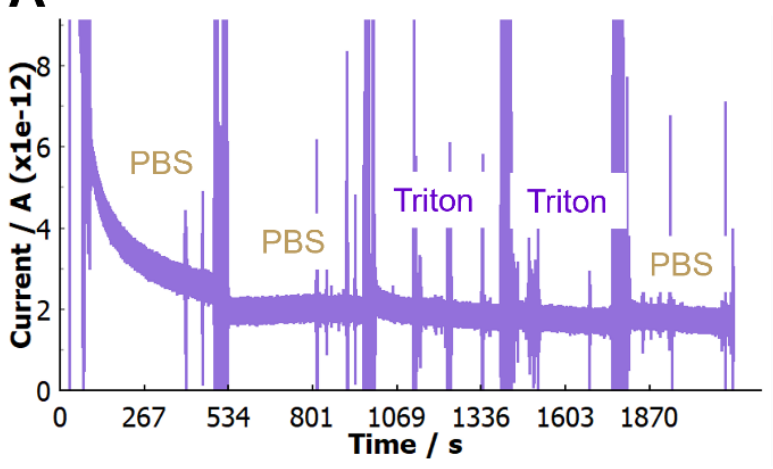

B

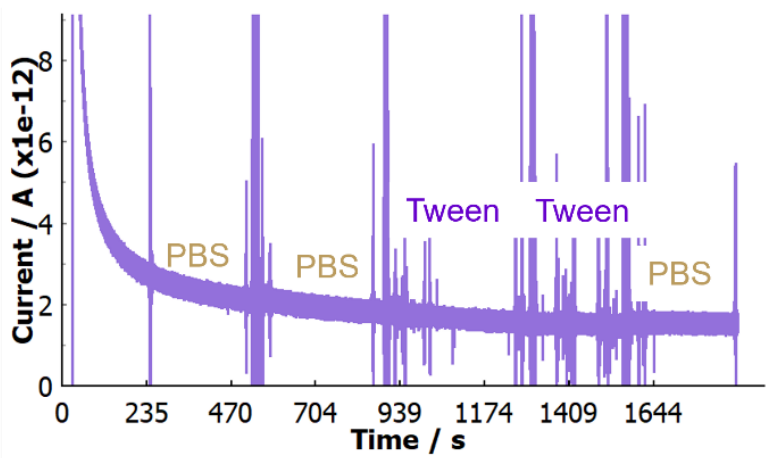

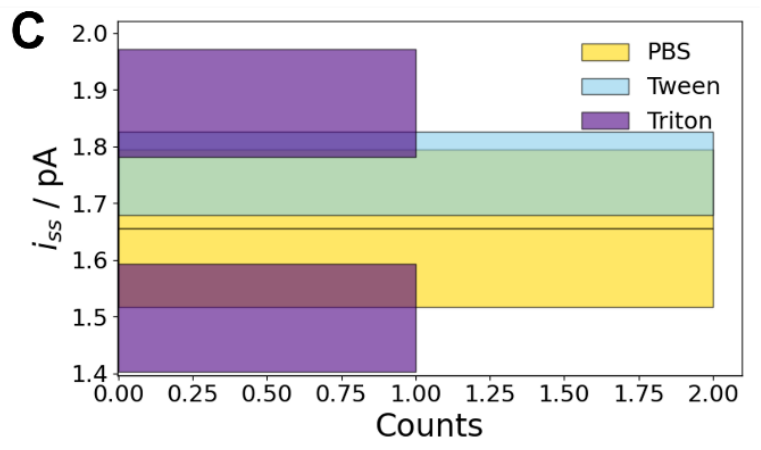

Figure S7: Effect of the addition of (A) 1\% Triton X-100, (B)1\% Tween-20 in PBS on the current response measured with GO biosensors immersed in PBS. (C) No increase in the steady state current is observed, confirming that both surfactants do not interfere with the recorded oxidation current. 


\section{References}

(1) Fuchs, S. A.; De Sain-Van Der Velden, M. G. M.; De Barse, M. M. J.; Roeleveld, M. W.; Hendriks, M.; Dorland, L.; Klomp, L. W. J.; Berger, R.; De Koning, T. J. Two Mass-Spectrometric Techniques for Quantifying Serine Enantiomers and Glycine in Cerebrospinal Fluid: Potential Confounders and AgeDependent Ranges. Clin. Chem. 2008, 54 (9). https://doi.org/10.1373/clinchem.2007.100412.

(2) Boselli, A.; Rosini, E.; Marcone, G. L.; Sacchi, S.; Motteran, L.; Pilone, M. S.; Pollegioni, L.; Molla, G. Glycine Oxidase from Bacillus Subtilis: Role of Histidine 244 and Methionine 261. Biochimie 2007, 89 (11), 1372-1380. https://doi.org/10.1016/j.biochi.2007.04.019. 